\title{
Exercício da cidadania e luta pela vida: precariedade das vidas de travestis e transexuais no estado de Alagoas
}

\section{Citizenship and struggle for life: precariousness of travesti and transexuals lives in Alagoas state}

\author{
Carolina Cavalcante Lins* \\ Marcos Ribeiro Mesquita*
}

\begin{abstract}
Resumo: O presente artigo traz resultados de uma pesquisa de mestrado realizada com ativistas do movimento social travesti e transexual da cidade de Maceió, concentradas na Associação das Travestis e Transexuais de Alagoas (ASTTAL). O texto trará uma discussão dos direitos humanos voltada para essa população e atrelada à questão da transfobia, através da noção de precariedade. A metodologia utilizada na pesquisa contou com um desenho variado, que abrangeu a observação participante, diários de campo e entrevistas semiestruturadas. Os resultados nos mostraram que tal violência direcionada às pessoas trans é encarada de uma maneira diversificada, trazendo à tona a culpabilização, o medo e a ausência de ações estatais que as retirem do lugar de quase humano no qual são inseridas.
\end{abstract}

Palavras-chave: Movimentos sociais trans. Cidadania. Violência.

\begin{abstract}
This article presents results of a master's research conducted with travesti and transexual social movement activists from Maceió city, concentrated in the Association of Travestis and Transsexuals of Alagoas (ASTTAL). The text provides a discussion of human rights related to this population and linked to the issue of transphobia through precariousness notion. The methodology used in the survey had a varied design, which included participant observation, field diaries and semistructured interviews. The results had shown that such violence directed to transgender people is viewed in a diverse way, bringing up blame, fear and the absence of state actions that remove them from the place of almost human in which they are inserted.
\end{abstract}

Keywords: Trans social movements. Citizenship. Violence.

Recebido em: 20/06/2016. Aceito em: 17/08/2016

\footnotetext{
" Mestre em Psicologia pela Universidade Federal de Alagoas (UFAL), no qual foi bolsista da Coordenação de Aperfeiçoamento de Pessoal de Nível Superior (CAPES). Graduada em Psicologia pela mesma Universidade. É integrante do Núcleo de Estudos em Diversidades e Política, na UFAL. Atua no campo de Processos Psicossociais. Suas temáticas de interesse são: gênero, sexualidade, participação política, juventudes e saúde. E-mail: caroll_lins@hotmail.com.

* Doutor em Psicologia (Psicologia Social) pela Pontifícia Universidade Católica de São Paulo. Mestre em Sociologia Política pela Universidade Federal de Santa Catarina (2001). Graduado em Psicologia pela Universidade Federal da Paraíba (1997). Atualmente é professor da Universidade Federal de Alagoas, onde ensina no curso de Psicologia, no Programa de Pós-graduação em Psicologia e tem se debruçado a estudar gênero, política e sexualidade desenvolvendo várias pesquisas nessa área. E-mail: marcos.mesquita@ip.ufal.
} 


\section{Introdução}

O artigo a seguir relata resultados de uma pesquisa ${ }^{1}$ de Mestrado em Psicologia realizada durante dois anos com militantes travestis e transexuais da cidade de Maceió, no estado de Alagoas. Estas se organizam através da Associação das Travestis e Transexuais de Alagoas (ASTTAL), uma organização não governamental constituída exclusivamente por pessoas trans (em sua maioria negras), voltada para o combate da transfobia e outras demandas e especificidades desse público, sendo essa associação uma das poucas da cidade com esse perfil, dado o predomínio de grupos exclusivamente gays.

Ao realizar uma pesquisa que intentou compreender o exercício da cidadania de um grupo de pessoas trans no meio político nos deparamos com diversas questões vinculadas a esse tema. Uma das mais pertinentes e preocupantes à população travesti e transexual é o processo de desumanização pelo qual passam, entendendo desumanização enquanto lugar de vulnerabilidade induzida e de produção de abjeções.

Tal desumanização tem resultado em altos índices de violência direcionados à população trans, a qual denominaremos de transfobia. Essa problemática diz respeito não só à violência física, mas também a todas as modalidades de violência possíveis, cerceando não só o direito à vida, como também o exercício da cidadania, indicando um mecanismo estrutural que atua nas esferas das relações sociais, econômicas e estatais. Desse modo, as diversas formas em que se apresenta são invisibilizadas, e apenas através da aproximação com o movimento é possível compreender a dimensão que toma na vida dessas sujeitas, uma vez que os processos de marginalização, exclusão e agressividade aumentam a cada ano que passa.

Tal situação das travestis e transexuais em Alagoas provoca uma restrição na liberdade de circular por determinados espaços, no modo de serem percebidas como pessoas, cidadãs. Além disso, o mesmo preconceito que regula essa violência, também restringe radicalmente o acesso à educação, ao mercado de trabalho, à moradia digna, à segurança pública, dentre

\footnotetext{
${ }^{1}$ Essa pesquisa foi financiada pela Coordenação de Aperfeiçoamento de Pessoal de Nível Superior (CAPES).
}

tantos outros fatores. Assim, a maneira como o Estado e parcelas da sociedade tem lidado com essa população, viola direitos humanos, demonstrando que embora estejam "protegidas" na forma da lei, se faz necessário lutar para que sejam cumpridas ou ainda reivindicadas a criação de políticas específicas que façam valer seus direitos.

Considerando a região em que Alagoas se insere, o nordeste do país, observam-se índices elevados de violência, apresentando o maior número de homicídios contra LGBTs no último ano (GGB, 2015). Além disso, tendo passado só a metade do ano de 2016, 22 pessoas trans foram assassinadas na mesma região, de acordo com dados hemerográficos coletados pelo Grupo Gay da Bahia (GGB, 2016). Se aliarmos tal estatística ao crescimento exponencial nos números de feminicídios (WAISELFISZ, 2015), assassinato de jovens (WAISELFISZ, 2014), e o agravante do número de homicídios por arma de fogo ter quase duplicado (WAISELFISZ, 2015), tudo isso na última década, observamos o caráter peculiar da proliferação da violência nessa parcela do país, o que reforça a necessidade de se compreender como essas intersecções influenciam na prática de crimes transfóbicos em tal contexto.

Para além dos homicídios, há muitas outras formas de violência transfóbica que vem sendo subnotificadas ao longo dos anos; de acordo com relatório elaborado pela Comissão Interamericana de Direitos Humanos (CIDH), na maior parte dos países da América a ausência de sistemas institucionais eficazes que registrem e denunciem ações violentas motivadas por preconceito contra a população trans mascara o verdadeiro alcance que a violência possui, além de causar uma subestimação do número de incidentes $(\mathrm{CIDH}$, 2015).

Ainda que haja sistemas de registro institucionais, as vítimas costumam evitar a formalização de denúncias dessas experiências nesses espaços por temerem violações de confidencialidade e represálias, e acabam por denunciar tais acontecimentos a representantes e grupos de movimentos sociais da sua cidade $(\mathrm{CIDH}$, 2015), de modo que a dimensão da violência que atinge a população trans numa determinada região e a maneira como ela é enfrentada só poderiam ser compreendidos através dessas(es) 
representantes que conhecem de perto a realidade vivenciada por essas sujeitas e por esses sujeitos.

Visto desse modo, a reivindicação para que seus direitos sejam cumpridos e que políticas públicas sejam criadas não são processos simples, exigem uma luta que se concretiza "dado os conflitos permanentes que surgem quando irrompem no cenário político-social atores, invariavelmente considerados cidadãos de segunda classe, reivindicando direitos plenos, tratamento digno e respeitoso e atenção básica diferenciada" (BRASIL, 2002, p.61).

É importante ressaltar que com o avanço do movimento trans há uma luta incessante pautada na busca por direitos civis. Como dissemos, embora muitos dos quais reivindicam já estejam previstos na constituição, aparentemente não se aplicam a essas sujeitas que, dada sua invisibilidade e abjeção, não conseguem acessá-los. Tal realidade tem se convertido na precarização das vidas dessas sujeitas, conforme observaremos ao longo deste texto.

Assim, a problematização dessa realidade se justifica à medida em que a população trans da capital de Alagoas tem seu cotidiano permeado por altos níveis de analfabetismo, pobreza e violência. Essa realidade se agrava à medida que a hostilidade direcionada às militantes é acrescida da discriminação racial, entendida aqui como processo no qual determinados grupos são subalternizados e tratados de maneira desigual e pejorativa por determinados traços raciais. Assim "grupos considerados superiores obtém privilégios em relação aos outros grupos, considerados inferiores" (EURICO, 2013, p. 294).

Aliada a questões raciais, o fator socioeconômico da população trans feminina da capital alagoana, e as militantes da ASTTAL aí incluídas, tem seu peso, conforme apontado. Além de terem seus gêneros negados na maior parte do tempo, também são alvo de uma violência que continua a atingir mulheres negras, com recorte para classes mais baixas. Contudo, há um agravante para a invisibilidade dessa transmisoginia nos mapas da violência de mulheres, o que as torna ainda mais vulneráveis, uma vez que suas mortes não são notificadas ou entram em índices específicos.

Desse modo, pretendemos discutir alguns dos processos que tornaram estas sujeitas como menos relevantes para o coeficiente social no contexto de uma cidade nordestina, assim como debater a perspectiva das ativistas sobre a violência que as atinge, que muitas vezes as tornam menos humanas e menos cidadãs.

\section{Relação performance-precariedade}

Para problematizar o processo de precarização pelo qual essa população passa faz-se necessário rever alguns vínculos da construção e naturalização da abjeção dessas vidas com uma não conformidade ao binarismo de gênero. Ao refletir sobre essa perspectiva sexo-gênero é possível apontar os cruzamentos entre esses dois aspectos na apresentação do performativo, compreendendo tal apresentação como uma (re) produção de identidades socialmente construídas, pensando em expressões, corporalidades, materialidades e discursos representados por aquilo que se supõe ser um homem ou uma mulher (BUTLER, 2014).

Deste modo, é possível definir a ontologia do gênero e seu caráter compulsório enquanto uma "estilização repetida do corpo, um conjunto de atos repetidos no interior de uma estrutura reguladora altamente rígida, a qual se cristaliza no tempo para produzir a aparência de uma substância, de uma classe natural do ser" (BUTLER, 2014: p. 59). Sendo o sexo constantemente generificado, sua posição condiciona uma propagação parodística dos sentidos do gênero, proporcionando uma ideia de que este último seria o grande fundador da identidade.

Pensando em movimentos sociais travestis e transexuais, por exemplo, que possuem um de seus nortes na questão da identidade, como entender tal desconstrução? Desconstruir a noção naturalizada do gênero, como se é concebido e reproduzido, não indica que o viés identitário do gênero deva ser desprezado. Butler (2014) argumenta que justamente por se tratarem de repetições de atos, os gêneros podem se constituir (ainda que de maneira precária) enquanto identidades, devido ao seu caráter temporal e cultural.

A autora nos traz algumas pistas para compreender essa questão, que aparentemente estariam interligadas. A primeira delas, diz respeito ao simples fato de definir-se ou ser definida enquanto pertencente a um sexo-gênero (entendendo que ter um gênero é considerada 
uma obrigação social), de maneira que definir esse sexo já possui um caráter coercitivo, por se tratar de uma performatividade do institucional sobre os sujeitos, que define suas percepções através da noção de que há características sexuais divididas em dois blocos.

Asegunda aparece, em algum ponto, como consequência da primeira, pois se há uma obrigação em possuir um determinado gênero, logo há um mecanismo social que a regula; de modo que o gênero aparece como estratégia de sobrevivência cultural, e porque inserido num sistema político de compulsoriedade, sua identificação e performatividade deve apresentar certa coerência, uma vez que acarretam em consequências de ordem punitiva.

A performatividade poderá inscrever essas sujeitas na política através do poder de visibilizar suas existências e suas precariedades. Consequentemente, ainda que possuam existências não autorizadas por regimes legais e estejam parcialmente cobertas pela lei, põem seus corpos nas ruas, sem que haja um protesto ou uma demanda específica, podendo tornar visíveis condições precárias de vida (BUTLER \& ATHANASIOU, 2013).

Ao chamar a atenção para a precariedade e tomar posse de uma visibilidade, tais sujeitas proporcionam um conflito entre as concepções que separam vidas visíveis (e vivíveis) e vozes audíveis, de vidas não visíveis (e não vivíveis) e vozes que não podem ser ouvidas; especialmente no caso de travestis e transexuais podemos citar, por exemplo, a performance da transexual Viviany Beleboni na $19^{\circ}$ Parada LGBT de São Paulo, em 2015, que apareceu crucificada em um dos trios elétricos que desfilavam pela Avenida Paulista. Com este ato, Viviany não só provocou choque, como revolta para aqueles que não reconheciam seu ato enquanto representação simbólica da precariedade da vida que transexuais e travestis possuem. Ao afirmar em entrevista "representar a agressão e a dor que a comunidade LGBT tem passado" (DANTAS, 2015), Viviany ultrapassa a representação de agressão e dor, conforme relatou sua intenção, e performativiza a maneira cruel como travestis e transexuais são violentadas e assassinadas cotidianamente, assim como enluta as mortes de pessoas LGBTs.

Esta mesma performance chama a atenção para o poder político dos corpos, especialmente quando tais corpos estão implicados em condições incomuns de desapropriação de direitos e posições de descartabilidade (BUTLER \& ATHANASIOU, 2013), condições estas que apontam para o que se caracteriza enquanto vidas precárias. Todavia, conseguir visibilidade implica em adquirir reconhecimento nesse contexto?

O tornar visível, ou tornar-se apreensível, nos termos de Butler (2015), não implica necessariamente em reconhecimento, algo que esses corpos e essas sujeitas provavelmente almejem. De acordo com a autora, a apreensão de um sujeito indica uma maneira de conhecer, que ultrapasse a experiência visual, mas que não atinge o reconhecimento ainda. Ao passo que ser inteligível enquanto vida se torna pré-condição para as normas do reconhecimento. Segundo Butler (2015, p. 17)

Os esquemas normativos são interrompidos um pelo outro, emergem e desaparecem dependendo de operações mais amplas de poder, e com muita frequência se deparam com versões espectrais daquilo que alegam conhecer. Assim, há "sujeitos" que não são exatamente reconhecíveis como sujeitos e há "vidas" que dificilmente - ou, melhor dizendo, nunca - são reconhecidas como vidas.

Dessa forma, ainda que a violência denunciada por Viviany em sua performance seja supostamente conhecida, o fato de ter havido grande moção contra este ato político nos diz quais vidas são reconhecidas, e em consequência, enlutadas.

Isto nos conduz diretamente à precariedade, pois, ao entendermos a precariedade enquanto condição da vida em sociedade, ser precário implicaria em uma exposição constante a aquilo que conhecemos e aquilo que desconhecemos (BUTLER, 2015). Porém, o fato de haverem vidas mais precárias que outras denuncia uma desigualdade de condições de vida e convivência, pois se viver já é supostamente precário, isso indica uma linearidade onde não deveriam haver vidas menos vivíveis e menos reconhecíveis em detrimento de outras.

Semelhante questão aponta para uma importante ressalva feita por Butler (2015), onde assevera que a precariedade também se constitui enquanto uma circunstância induzida politicamente por dois fatores: o primeiro seria a 
constante exposição "à violência arbitrária do Estado que com frequência não têm opção a não ser recorrer ao próprio Estado contra o qual precisam de proteção" (BUTLER, 2015, p.46-47); e o segundo seria a distribuição extremamente desigual de recursos financeiros, assim como uma maior exposição de algumas populações à violência, baseada numa concepção de raça, classe, gênero ou nacionalidade.

A denúncia dessa condição maior de precariedade pelos movimentos sociais pode implicar em um não reconhecimento sob a acusação de vitimização, de modo que em vez de endereçar injustiças, desigualdade e opressões (BUTLER \& ATHANASIOU, 2013), tais movimentos são acusados de usarem da posição de vítima para conseguir "direitos especiais", o que indica que nem todos os sujeitos num contexto social contam para a conjuntura política. Ainda, segundo as autoras, o reforçamento da imagem de vitimização pode acabar reforçando uma forma de política paternalista do Estado, de modo que alguns movimentos baseariam sua ação política nas concessões do Estado, institucionalizando em alguma medida um processo que se entenderia como fomentador de resistência popular.

Por outro lado, vale ressaltar que a vulnerabilidade não é sinônimo de precariedade, embora faça parte desta última. A vulnerabilidade se refere a um estado e se mostra mais relacional que a precariedade, de forma que, se estamos falando de uma sujeita que é travesti, negra e pobre, sabemos que sua precariedade é maior em relação a de outros sujeitos que possuem privilégios de gênero, raça e classe social. Porém, sua vulnerabilidade se apresentará nos momentos em que sua vida necessite ser reconhecida, seja pelo outro, seja pelo Estado, na forma da polícia ou da justiça, por exemplo.

A condição de vulnerabilidade do sujeito não se supera meramente através dos processos de resistência, embora torne-se um ponto fundante para a mobilização desse sujeito. Desse modo, ao formar coletivos esses corpos precários e vulneráveis demonstram resistência política ao expor sua vulnerabilidade publicamente. Os movimentos trans possuem um importante papel no que condiz a exposição dessa vulnerabilidade e ao enfrentamento e reformulação de normas que são investidas no corpo. Como nos diz Butler (2006) esses movimentos questionam ideais corporais e com isso também contestam uma série de normas que prescrevem quem serão os sujeitos viáveis para se inserirem na esfera política.

Aqueles que são considerados inviáveis na esfera política se configuram enquanto identidades abjetas, uma vez que representam uma vida discursiva não questionada, que passa despercebida e que, consequentemente, ainda não tornou-se real. Dessa maneira, a abjeção não se volta exclusivamente para categorias como gênero, sexo e heteronormatividade, abarcando uma série de vidas que não são consideradas enquanto tais e corpos que possuem suas materialidades menosprezadas (PRINS \& MEIJER, 2002).

\section{Situando a ASTTAL}

AAssociação das Travestis e Transexuais de Alagoas começou a ser organizada e teve suas atividades iniciadas no ano de 2009. De acordo com as militantes, a associação surgiu como uma maneira de organizar a população travesti e transexual para combater a violência sofrida (em especial a policial) nas áreas de prostituição. A violência estatal contra a população trans certamente tem sido um disparador para que a mesma se organize e lute contra tal violação, sendo essa realidade recorrente em vários estados do país conforme aponta Carvalho (2011).

Outro motivo foi a necessidade de criar um espaço voltado exclusivamente para travestis e transexuais, pelo fato das militantes afirmarem que suas demandas eram constantemente negligenciadas em movimentos plurais, isto é, LGBTs, conforme nos explica Cris de Madri, uma das militantes entrevistadas:

O grupo surgiu, surgiu quer dizer ressurgiu, porque antes havia um grupo que eu era coordenadora geral, só que devido a algumas viagens que eu fiz mudou de coordenadores, e que no qual não voltou mesmo pras mãos de uma travesti, uma transexual, ficou mais voltada pra um público gay e transformista, aí eu vendo que não estava contemplada no q..., no que eu não me contemplava naquela associação aí houve a necessidade da criação dessa, da ASTTAL, para nós travesti e transexuais. (Cris de Madri, Entrevista em 6 de Janeiro de 2016). 
Como várias outras associações ligadas aos movimentos de travestis e transexuais, sua constituição se dá no modelo das ONGs-AIDS, com a finalidade de ter um campo aberto para a participação em projetos voltados ao combate de DSTs, HIVIAIDS e Hepatites Virais. Assim, grande parte dos projetos provenientes do Ministério da Saúde ou das Secretarias Estadual e Municipal de Saúde tem norteado as ações da associação, que tem atuado no sentido de promover saúde e instruir a população trans para o autocuidado, com o objetivo de reduzir a vulnerabilidade a qual estão expostas, além de prolongar suas expectativas de vida. Entretanto, a atuação da ASTTAL não se restringe ao campo da saúde e do combate às DSTs. A associação atua no estado de maneira ampla, estabelecendo vínculos com a área do trabalho e da educação, além de atender aquelas que vivem em situação de rua.

É importante ressaltar que a ASTTAL não está isolada do cenário político nacional. Sendo esta vinculada à Associação Nacional de Travestis e Transexuais (ANTRA), nota-se uma rede de informações e parcerias estabelecidas entre as militantes de Alagoas e aquelas provenientes de outros estados do Brasil que faz com que a associação possa pautar muitas de suas lutas em consonância com as que estão sendo pleiteadas por e para travestis e transexuais a nível nacional, além de proporcionar uma outra visão sobre seu próprio estado.

\section{Dimensões metodológicas}

Nossa investigação adotou uma metodologia participante, uma vez que compreendemos a pesquisa como um processo de convivência entre sujeitos, conforme apontam Sato e Souza (2001). Houve uma preocupação com o modo como esse conhecimento seria produzido, quais seriam seus propósitos e a quem se destinaria; pensando assim, foram priorizadas as idas à campo, para conhecer a realidade que se pretendia estudar e para estreitar os vínculos com aquelas que foram as interlocutoras da pesquisa, de maneira que fosse possível compreender o ativismo trans através daquelas que o protagonizam e da participação no próprio movimento.

Essa inserção no campo foi iniciada no primeiro ano de pesquisa e foi realizada, inicialmente, num ritmo mais lento, onde as idas eram mais pontuais e vinculadas a reuniões ou eventos marcados. Posteriormente, no ano seguinte, as idas a campo se tornaram mais frequentes e menos restritas a encontros e ocasiões planejadas, fazendo com que a participação tenha se consolidado e vínculos mais estreitos se formassem.

Para registrar aspectos que havia passado a enxergar e entender durante as idas a campo, não haveria possibilidade de contar apenas com a memória para documentar o que vivenciava, o que aprendia e refletia; dessa forma, encontrei na escrita de diários de campo uma maneira de fazê-lo. De acordo com Weber (2009), essa ferramenta não mostra sua importância simplesmente por acumular informações sobre os diversos fatores relatados, mostra seu valor a partir do momento em que atualiza aos pesquisadores sobre a relação estabelecida entre eles e as sujeitas da pesquisa. O diário de campo também permite um distanciamento do que se está pesquisando, entendendo-o aqui no sentido de um olhar diferenciado sobre a própria imersão dos pesquisadores, que proporcione reflexividade sobre suas atuações e o processo de construção de conhecimento.

A escrita dos diários de campo começou num ritmo lento e em um ano tinha se acelerado de tal forma que em alguns a reflexividade ficava para os momentos de releitura dos diários já produzidos. Esse fato me chamou a atenção para a importância que a reflexividade teve na pesquisa, pois ao perceber que em alguns diários estava apenas descrevendo os ocorridos, sempre parava para pensar no que as "idas e vindas entre dois universos simbólicos" (FONSECA, 1999, p. 65) tinham me proporcionado naquele dia, e o que eu tinha aprendido. Ainda segundo o autor, essa ferramenta exige do pesquisador uma atenção especial para as discrepâncias entre discurso e prática, que as técnicas de entrevista sozinhas têm dificuldade de revelar.

Para além da participação na associação e acompanhamento das atividades das militantes, registradas em diário de campo, realizamos entrevistas com as mesmas como uma ferramenta importante para obter uma fala exclusiva dessas interlocutoras; foram sete entrevistadas no total, onde cada participante concedeu uma entrevista.

Utilizar entrevistas semiestruturadas proporcionou uma aproximação maior entre a prática das militantes, do ponto de vista da pesquisadora, 
e a maneira como as mesmas encaravam suas ações no campo da política; isto se deu a partir do momento em que relatavam atividades do movimento social, já descritas nos diários de campo, sob uma perspectiva baseada em suas vivências. Através dessa modalidade de entrevista, é possível viabilizar a oportunidade da pessoa expressar sua subjetividade através do mecanismo da fala, pois é por meio dessa fala expressa nas entrevistas que será possível conhecer particularidades das condições históricas, sócio-econômicas e culturais que permeiam o grupo pesquisado (MINAYO \& SANCHES, 1993).

Além disso, Laraña (1999) aponta que a linguagem não possui um caráter unívoco, mas apresenta variações substantivas que se relacionam diretamente com a natureza dos grupos sociais e da classe na qual o entrevistado está inserido, de maneira que se faz necessário compreender como falam e escrevem para que a informação concedida no momento de entrevista seja codificada e os processos de edificação dos movimentos sociais sejam entendidos.

Ambos os métodos combinados permitiram uma maior compreensão do ativismo político, não se comprometendo, contudo, com a possibilidade de captura-lo como um todo imutável. De acordo com Flick (2009) a observação participante pode fazer com que o pesquisador entenda enunciados dentro do grupo onde se insere como atitudes compartilhadas, e não o que realmente são: enunciados isolados.

Refletindo sobre tais aspectos, decidimos voltar a atenção não só para as entrevistas das militantes, como também suas atitudes e ideais, participando de ocasiões não institucionais de forma a desvincular a luta política de reuniões e eventos públicos. Tal decisão conferiu importância aos diversos momentos de fala e interação, como as conversas informais estabelecidas, por exemplo.

Vale pontuar que a maior parte das militantes desejaram ter seus nomes publicados, sem a necessidade de criação de nomes fictícios. A decisão das ativistas de não criar codinomes nas entrevistas se deu por estarem almejando visibilidade e reconhecimento pela atuação no movimento social. Os nomes fictícios que se apresentarem no texto foram criados pela pesquisadora a partir de registros de falas em diários de campo de eventos e reuniões realizadas pela
ASTTAL que foram trazidas para a análise. A criação desses nomes teve como finalidade proteger a identidade de interlocutoras que participaram mais pontualmente da associação, mas que não foram entrevistadas.

Além disso, optamos por diversificar a estrutura das entrevistas, de forma a destacar a diversidade de experiências das militantes. O roteiro de pesquisa consistiu em 16 questões base, porém o mesmo foi sendo alterado conforme cada entrevistada, tendo em vista que as sujeitas da pesquisa tem tempo e trajetórias diferentes na militância, assim como suas representatividades a nível estadual e nacional são distintas. Realizar as mesmas questões para todas seria desperdiçar uma série de experiências valiosas para se compreender a trajetória política das participantes e revelaria um enrigecimento na condução de uma etapa da pesquisa que se supõe dialógica.

As entrevistas foram gravadas e transcritas, e para analisa-las foi utilizada uma análise de conteúdo adaptada, conforme descrito em Campos (2004), onde foi possível elencar unidades de conteúdo, baseadas nos relatos mais constantes entre as entrevistadas e naquilo que se mostrou mais relevante ao movimento social. Para além dessa ferramenta, nosso olhar sobre as unidades e categorias foi direcionado pela Teoria da Performatividade, pela discussão de vidas precárias e pela interseccionalidade.

A primeira fase da análise constituiu-se através de uma leitura flutuante das entrevistas, de modo a se aproximar das informações a serem analisadas, compreender o contexto ao qual se referem e dar lugar às primeiras impressões sobre o material. Segundo Campos (2004), nessa fase as diversas leituras feitas devem proporcionar a identificação de ideias principais e seus significados gerais, possibilitando também que a pesquisadora possa transcender as mensagens explícitas contidas no material.

A segunda fase envolve os objetivos da pesquisa, uma vez que o conjunto de questões norteadoras da entrevista se baseou nos mesmos, e a escolha das unidades se refere à seleção de categorias mais abrangentes do texto. A última fase implica em agrupar as unidades de significado e transforma-las em categorias mais abrangentes. De acordo com Campos (2004), essa categorização é totalmente dependente do contexto da entrevista das participantes, fazendo 
com que a pesquisadora tenha que consultar o material diversas vezes, sempre intercalando-o com a experiência de campo, as teorias que embasam o estudo e os objetivos do mesmo.

Ao transformar as unidades em categorias levamos em conta, em primeiro lugar, a relevância do tema (Campos e Turato, 2009) encontrado nas entrevistas para o contexto e a população incluídos na pesquisa, e em segundo lugar, a frequência com a qual o tema apareceu nos relatos das militantes, de maneira que uma temática pouco explorada, mas pertinente, não seja negligenciada. Tal procedimento permitiu também que tivéssemos a oportunidade de executar as iniciativas de uma pesquisa interseccional, propostas por Platero (2014), como trazer à tona algumas questões ou problemas sociais comumente invisibilizados, por exemplo.

Após diversos olhares sobre o material de análise foi possível estabelecer algumas categorias. Todas apresentaram recorrência na fala das militantes e eram extremamente relevantes; dentre as quais selecionamos a categoria transfobia para esta discussão, por se tratar de uma pauta atual e marcante das violações que travestis e transexuais sofrem diariamente.

\section{Transfobia: entre "Se impor o respeito" e não contar como vida}

Um dos resultados da pesquisa se referiu ao quesito transfobia, discutido ao longo da participação no movimento e destacado nas entrevistas por muitas das militantes. Conforme apontado anteriormente, compreendemos este termo enquanto atos (institucionais ou não) de violência endereçados à população travesti e transexual motivados especialmente pela identidade de gênero.

Entretanto, a visão e a compreensão de transfobia que guiará nossa análise nesse momento será a das militantes, que ao serem questionadas sobre o enfrentamento da transfobia nos ofereceram respostas que se subdividem em três esferas, como é possível entender a seguir.

\section{A transfobia suportável}

A busca por comportamentos específicos que atendam a cisnorma se tornou algo cotidiano para muitas travestis e transexuais do movimento; dessa maneira, não há como culpabilizá-las por desejarem atingir um ideal feminino compatível com normas sociais específicas, que lhes garantiriam possibilidade e inúmeros privilégios. Esses dois últimos, em especial, tem se mostrado influentes no que diz respeito a possibilidade de sofrer episódios de transfobia ou não, embora o único fator determinante seja o ódio e a ignorância que movem as pessoas que as agridem. Assim, tentaremos compreender a maneira como as entrevistadas moderam seus comportamentos de acordo com esses pressupostos e ao se deparar com tais pessoas, como maneira de tentar evitar episódios de transfobia ou apenas torna-los suportáveis.

Ah, eu acho que, em primeiro lugar a pessoa deve se impor o respeito, a partir do momento que ela tá se impondo respeito, ela tá dizendo tudo. (Cléo Santos, Entrevista em 6 de Janeiro de 2016)

Agora eu falando por mim existe coisas que eu relevo, que eu ignoro, de pessoas ignorantes, com falta de capacidade de se encontrar é no meio social, então existe coisas que eu ignoro. Agora existe coisas que eu ver que não dá pra passar então eu corro atrás dos meus direitos [...] agora em questão de homofobia, picuinhas, piadas, charadas eu ignoro, ignoro porque é, a gente nos dias de hoje, a gente tem que saber é, certas coisas aprender a engolir que senão a gente vai brigar com o mundo inteiro. (Cristiane Effré, Entrevista em 27 de Outubro de 2015)

Já sofri bullying, xingamento, mas nunca procurei o meus direitos, sempre me comportei, sempre procurei o meu lugar, tá entendendo? Não dou cabimento, não começo a xingar nem nada, pra não ter agressão. [...] Fico na minha. [...] Assim, procurar o meu lugar ficando no meu lugar, quieta, não discuto nem nada, ta entendendo? Porque tem muitos que discute, né? E acaba sendo agredida. Tem muitos que não procura denunciar com medo, nunca fiz isso. Até agora porque não teve precisão, tá entendendo? Porque se um dia eu tiver precisão, eu procuro meus direitos, eu luto pelos meus direitos. (Andreza Fernandez, Entrevista em 17 de Dezembro de 2015)

Nesse caso, percebemos uma crença de que a maneira como se interage socialmente é enxergada como determinante da possibilidade de sofrer violência, ao mesmo tempo em que 
constatamos que a violência verbal é considerada como uma forma de transfobia suportável pelas militantes, atrelando a busca por punição de casos de transfobia quando ligadas à violência física. A ação de tentar relevar algumas atitudes transfóbicas em detrimento de outras formas de transfobia parece nos mostrar dimensões distintas: medo e sabedoria.

Ainda que sejam militantes e vistas como pessoas empoderadas, não há como estas ignorarem que o Brasil ganhou o indigno título de país em que mais se mata travestis e transexuais ao atingir a marca de 100 mortes anuais nos últimos seis anos, conforme reporta Cazarré (2015). Também não há como ignorar as próprias experiências vivenciadas ao tentar responder à altura atitudes de discriminação e violência verbal. A reação de medo a toda essa onda de violência destinada a elas demonstra que compreendem os riscos que correm ao tentarem sair momentaneamente de um lugar de humilhação.

A maneira como reagem por medo de que suas atitudes gerem consequências negativas para si mesmas revelam também uma sabedoria adquirida através de anos vivenciando suas reais identidades de gênero, no lugar das performances do gênero que lhes foram atribuídas ao nascer, e os problemas sociais que isso pode trazer; ou mesmo através da experiência no movimento social, por ter que lidar com casos de violência de sua comunidade a todo momento. Estes exemplos, dentre inúmeras possibilidades existentes indicam que as militantes sabem estar sofrendo transfobia nos casos que descrevem, mas também tem conhecimento de que ao reagir a precariedade de suas vidas poderia se tornar ainda maior.

Assim, a ideia de "ficar na delas" ou de "se impor o respeito", isto é, não discutir ou brigar, seria uma tática de "redução de danos" para convivência no meio social e para tentar evitar um (novo) episódio de agressão. Tal compreensão da transfobia revela as infinitas maneiras que a mesma pode assumir para essas sujeitas, demonstrando também que preferem suportar esse tipo de violência em muitos casos a "procurar seus direitos" e denuncia-la em delegacias, onde sabem que haverá uma desrealização desse tipo de violência, acarretando em riscos ainda maiores.
A desrealização da violência de gênero tem implicações para compreender como e por que certas apresentações de gênero são criminalizadas e convertidas em patológicas, como os sujeitos que transgridem o gênero se arriscam a ser internados e encarcerados, por que a violência contra as pessoas transgênero não se reconhece como tal, e por que às vezes a inflige os próprios Estados, que deveriam estar protegendo tais sujeitos (BUTLER, 2006, p. 308-309, tradução nossa).

Em contrapartida, conserva-se um ideal de que aquela que sofre a violência é, na realidade, a grande responsável pelo episódio, reforçando uma imagem de submissão e recato (ainda) vinculada ao feminino, em detrimento da figura da "travesti bagunceira", que briga e discute, tão rechaçada pela população e pelo próprio movimento LGBT (FIGARI, 2007). Esse processo de culpabilização de si mesma oculta a precariedade de suas vidas implicada na vontade do outro de praticar a violência (BUTLER, 2015), constituindo a transfobia como um campo no qual as travestis e transexuais não se inserem por vontade própria através da repreensão de quem as agride.

Durante a experiência de campo, notamos convergências com algumas falas nas entrevistas, pois uma das militantes sempre começava seus discursos em público afirmando que elas todas estão ali lutando e mostrando que travesti não é só "mostrar peito e bunda" ou "fazer escândalo", que é necessário "se comportar" mesmo em situações de discriminação.

Minha fia, no estado é a gente é, qual é o nosso trabalho, a gente ensina as menina comportamento, como tem que se vestir, se comportar durante a sociedade, mostrar não a violência, não, não assim se expor tanto como as pessoas pensam "ah, que travesti é, é bagunceira", não, não pode ser assim, é com diálogo, você tem que resolver as coisa com diálogo e mostrar pras pessoas o que você é, não a sua aparência, né? (Natasha Kiss, Entrevista em 11 de Novembro de 2015).

Essa fala, assim como as anteriores revela tensões entre as atitudes tomadas em benefício de suas próprias proteções e manutenção de uma sobrevivência, e a culpabilização daquelas que são vítimas de transfobia. A ideia de que mostrar o peito e a bunda retirariam a legitimidade de alguém ou incitariam/atrairiam violência para si 
retorna para o silenciamento de vozes e corpos femininos, encerrando-os na esfera do privado e da passividade, ao passo que também reafirma um ideal machista de que vozes e corpos masculinos são superiores e possuem legitimidade dada de antemão, pois derivadas de uma "natureza hierárquica".

Trata-se de uma questão delicada que constitui linhas tênues entre formas de proteção e culpabilização, seja de si ou de outras. Tive a oportunidade de presenciar a materialização dessas linhas durante a experiência de campo, da qual trago dois casos retratados em diário de campo:

Stephany ${ }^{2}$ havia chegado reclamando que tinha sido roubada pelo seu novo namorado. Cris pergunta "de novo, Stephany?", indicando que isso ocorria com frequência a ela, e continuou: "também a senhora só se envolve com erể, aí dá nisso", indicando que ela seria culpada pelo ocorrido e deixando-a mais triste. (Diário de campo de 21 de Dezembro de 2015).

Samantha falava sobre seu marido, o qual já havia Ihe roubado quatro vezes (!), não pude conter a surpresa e perguntei do alto de minha ignorância "e você ainda está com ele?" [...]. (Diário de Campo de 29 de Janeiro de 2016).

Percebemos assim, dois casos de violência patrimonial que apontam, no primeiro caso, para a culpabilização de uma pessoa trans por não se privar do relacionamento com erês e "proteger-se" desse tipo de violência, invisibilizando assim o único culpado pela mesma; e no segundo, para os relacionamentos abusivos que tem se tornado cada vez mais comuns entre as travestis e transexuais, reforçando a ideia de "ficar no seu lugar", como afirmou Andreza, em vez de se manifestar por medo de represálias. Embora exista a possibilidade de não se tratarem de violências transfóbicas, em ambos os casos não se considera a viabilidade de "fazer escândalo" ou denunciar publicamente, pois correm riscos de serem violadas novamente, adiando a necessidade de buscar seus direitos.

\footnotetext{
2 Tanto Stephany quanto Samantha são nomes fictícios e aleatórios, utilizados para proteger as identidades das pessoas descritas.

${ }^{3}$ Homem muito jovem.
}

Com relação a essa busca de direitos apenas quando há "precisão", isto é, em casos extremos, como dá a entender, parece ser pertinente questionar que direitos de fato são esses, em quais parcelas dos direitos civis as mesmas se "encaixam". Isto porque se a lei não reconhece travestis e transexuais em sua legitimidade, o que as mesmas denunciarem será igualmente desprovido de valor, fazendo com que as mesmas sejam dessubjetivadas pela própria lei (BUTLER \& ATHANASIOU, 2013). Todavia, ainda que não haja vontade dessas militantes em serem reconhecidas dentro de um modelo de sistema transfóbico e misógino, há casos em que não é possível fugir desse reconhecimento, como no caso de necessitarem ser amparadas por leis que punem o estupro ou a agressão contra pessoas do gênero feminino.

\section{Foi executada, mas não por ser travesti/ transexual}

Apesar da luta da associação contra a violência dirigida a essa população, as definições do que seria um crime transfóbico aparentam ainda estar em debate. No entanto, é possível dizer que incluem dimensões tanto simbólicas quanto físicas. Os xingamentos, o desrespeito, o não reconhecimento enquanto sujeitas/vidas tão reclamados por elas, certamente, materializam a transfobia nesse primeiro nível. Aqui discutimos a transfobia no nível da violência física e de sua letalidade, como elas compreendem, e que elementos trazem para a política.

Assim, se na discussão anterior a violência simbólica e verbal ganhou notoriedade, aqui a violência infligida no corpo se destaca, pois se trata de algo presente na vida de travestis e transexuais, isto unido à questão de ocorrerem inúmeros assassinatos dessas pessoas no Estado que são notados e enlutados apenas pelas participantes do movimento. Entretanto, isso não é característica exclusiva de Alagoas, no país inteiro os números de mortes não correspondem à realidade pelo simples fato de não serem notificados como transfobia, e sim como uma morte de alguém do sexo masculino que atendia por um apelido feminino ' $x$ '. Os próprios jornais revelam como os boletins de ocorrência em delegacias são elaborados, descrevendo essas sujeitas como homens homossexuais e 
apontando que há suspeitas (quando há) de crime motivado por homofobia.

Um relatório de violência homofóbica (que abrange LGBTs) elaborado pela Secretaria de Direitos Humanos do Brasil, referente ao ano de 2012, revela que em dados hemerográficos $40 \%$ de vítimas de violência indicaram travesti como identidade de gênero, e apenas $0,33 \%$ como transexual; já nos dados do poder público federal, apenas $1,47 \%$ das vítimas foram identificadas como travesti e $0,49 \%$ como transexual, "denotando a crescente invisibilização de um dos segmentos populacionais mais vulneráveis às violências e homicídios da sociedade brasileira" (BRASIL, 2013, p. 24) conforme o próprio relatório aponta. O único relatório atual que cruza dados de identidade de gênero com estados do país foi elaborado e publicado em 2014 pelo Grupo Gay da Bahia (GGB), onde se reporta que quatro pessoas trans foram vítimas de assassinatos em Alagoas (embora saibamos que há muitos que não chegam à esfera institucional ou aos próprios movimentos LGBTs e não são contados), em contraste com as 134 travestis mortas no país ao longo desse ano (GGB, 2015).

De acordo com relatório sobre violência contra pessoas LGBT do ano de 2015, publicado e elaborado pela Comissão Interamericana de Direitos Humanos (CIDH) em parceria com a Organização dos Estados Americanos (OEA), na maior parte dos países da América a ausência de sistemas eficazes que registrem e denunciem ações violentas motivadas por preconceito contra essa população mascara o verdadeiro alcance que a violência possui, além de causar uma subestimação do número de incidentes. Mesmo quando há sistemas de registro, as vítimas costumam evitar denunciar tais experiências por temer extorsões, violações de confidencialidade e represálias, demonstrando que tais sistemas ainda se constituem de maneira preconceituosa. (CIDH, 2015)

Pelo fato da violência ser uma realidade constante para elas desde que passam a assumir suas identidades de gênero espera-se que tenham opinião sobre o tema, sejam militantes ou não. O fato de algumas militantes terem presenciado violências praticadas pelas próprias travestis e transexuais contribui em alguma maneira para que se enxergue a transfobia de outra maneira, e passem a crer que nos casos de assassinato há outros elementos determinantes, conforme observaremos:

[...] mas nem tudo que é ligado à travesti e transexuais, a violência, algumas violência posta à elas, nem tudo isso é transfobia não, é relacionada também a outras coisas que tem, vem por trás. (Cris de Madri, Entrevista em 6 de Janeiro de 2016).

Aí o cliente vinha depois e executava através de tiros, quer dizer, ali ele vinha e matava, na época, matava essas travesti que morreram não era por ela serem travestis e transexuais, era pelo ato dela ter com... é, ter feito um delito com esse cliente[...]. (Cris de Madri, Entrevista em 6 de Janeiro de 2016).

[...] na Avenida se prostituindo existe muita, muitos acidentes de, de homofóbicos, acidentes digamos transfóbico mesmo de assassinatos. (Eryka Fayson, Entrevista em 1 de Dezembro de 2015).

Certamente, nem todos os assassinatos de travestis e transexuais podem ser comprovados enquanto transfobia, algumas travestis são conhecidas por roubarem recorrentemente seus clientes ou por adquirirem dívidas com drogas, fazendo com que sofram violências ou sejam assassinadas em decorrência disso. Um episódio de um desses atos ilícitos mais comuns, descritos por Garcia (2008) é roubarem todo o dinheiro da carteira de clientes que se recusam a pagar a quantia certa do programa, mesmo quando os mesmos a possuem. O retorno para essas atividades, porém, jamais passaria por denúncias institucionais (boletins de ocorrência) por partes dos clientes, dado o estigma que o envolvimento sexual com travestis carrega, e ultrapassa a mera tentativa de recuperação do dinheiro por meios próprios, culminando na execução delas.

A violência dos clientes era bem mais temida do que a policial, em virtude de ser muitas vezes mortal. Se era vista como uma resposta dos clientes a pequenos golpes, roubos e furtos por parte delas próprias, o grau de violência empregado e o desejo de humilhação das travestis implícito nos atos sugeria também a transfobia já referida. (GARCIA, 2008, p. 251).

Assim, a comprovação de que houve transfobia não implica que tais sujeitas estejam vivas para relatar o crime e sua motivação; o corpo sem vida a denuncia de forma gritante através dos 
requintes de crueldade utilizados para executa-las. De maneira que, ainda que seja um "acerto de contas" a motivação para um crime contra as mesmas, isso não apaga o que acontece em grande parte das execuções dessa população: o espancamento que precede os tiros, o pênis amputado ou os objetos introduzidos no ânus, por exemplo.

De acordo com Carrara e Vianna (2006) a maior parte dos crimes letais cometidos contra travestis e transexuais dizem respeito a crimes de execução, crimes que tem se tornado tão comuns entre elas que acabam sendo encarados com naturalidade pelo Estado, pela sociedade e na forma como é noticiado pelos veículos midiáticos. Até mesmo na fala das entrevistadas percebemos como o discurso institucional de que suas vidas não contam muito para o coeficiente social, e de marginalização, é absorvido e reproduzido por elas mesmas para explicar essas mortes, jogando para debaixo do tapete o ódio e a violência envolvidos nestas.

Notamos também que parece haver nas entrevistas uma equiparação entre transfobia, acidentes e crimes vinculados a "acerto de contas", entre intencionalidade e não intencionalidade, embora não haja possibilidade de separar a questão da vulnerabilidade em ambos. Para problematizar essas falas, faremos uma comparação baseada no contexto sob o qual a pesquisa se baseou.

Durante o período de realização da pesquisa (mas não em contexto vinculado a ela) conheci Adelaide, uma travesti moradora de rua que vivia no mesmo bairro onde moro, com a qual falava esporadicamente, porém, num dado mês passei a não encontra-la mais na volta para casa, até que semanas depois fiquei sabendo que ela havia morrido atropelada ao tentar salvar seu cachorro, claramente um acidente. Já durante a pesquisa de notícias relacionadas à morte de travestis em Alagoas, encontrei dois casos (dos inúmeros) que considerei emblemáticos para essa discussão, os quais cito a seguir, da maneira como foram reportados:

Duas décadas depois do martírio do vereador Renildo José dos Santos, sequestrado, torturado, morto e esquartejado em Coqueiro Seco, a travesti Soraia, de 39 anos, seria vítima de ato insano, cruel e covarde, no município sertanejo de Olivença. A violência praticada contra Soraia também chocou Alagoas.
Foi amordaçada, teve pedaços de madeira introduzidos no ânus e o pênis queimado com álcool. Sobreviveu alguns dias, com muitas dores, exalando odor de podridão. De seu intestino grosso, os médicos extraíram pedaço de madeira de 15 centímetros. (MARQUES, 2015).

A recuperação do travesti conhecido como "Flávia" ou "Babá" é fundamental para a polícia esclarecer um crime hediondo. Na madrugada de sábado, ele foi encontrado num buraco de fossa com quase 15 metros de profundidade. Com o pênis decepado e fratura exposta no fêmur, Flávia passou um bom tempo gritando por socorro até ser ouvida por vizinhos da casa onde mora, no Conjunto Cruzeiro do Sul, entre os municípios de Maceió e Rio Largo. (GONÇALVES, 2013).

Através desses três casos, é possível compreender o quanto podem se distanciar os crimes doloso (o caso de acidente narrado) e os culposos (os assassinatos noticiados). A grande questão incluída nisto é o fato de não haver crimes transfóbicos que possam ser considerados dolosos, pois a transfobia é um processo intencional, onde há intenção de causar dano ao outro, de tentar apagar um corpo e uma identidade de gênero incongruente com a cis/heteronorma. A violência incorporada na negação desses corpos é um empreendimento violento e sem frutos para restaurar normas de gênero, de modo a tornar ininteligíveis tais corpos, recusando, ao mesmo tempo, o desafio de se enxergar o mundo fora de naturalizações, fazendo com que tais crimes não sejam sempre e de imediato reconhecidos enquanto tais (BUTLER, 2006).

Segundo a CIDH (2015) muitas manifestações de violência contra essas pessoas se sustentam no desejo do perpetrador de castigar certas identidades de gênero, expressões e corpos que diferem de normas e papéis de gênero tradicionais, ou que infringem o binarismo. De acordo com a Comissão a maioria das mulheres trans estão imersas num ciclo de violência, discriminação e criminalização que perdura durante toda sua vida desde muito cedo, provocando exclusão e violência em qualquer instituição social na qual estejam inseridas. Esse ciclo mostra uma vulnerabilidade particular, fazendo com que sejam alvo de violência por parte da sociedade e 
da segurança pública, o que, em muitos casos, não as permite ultrapassar os 35 anos de idade.

Em conclusão, percebe-se que basear o entendimento da transfobia, especialmente nos casos de violência física e assassinatos, em estatísticas de violência dirigida a essas pessoas traz um importante debate sobre o poder que os dados de vitimização 4 tem para essa população. De acordo com Butler \& Athanasiou (2013) o discurso da vitimização oferece a possibilidade de obter uma organização política efetiva e de resistir àquilo que causa a violência, fortalecendo a sistematização de uma resistência, ao invés de se apropriar do discurso da vulnerabilidade sem que isso conduza a uma capacidade de responder a uma dada realidade.

\section{A humanidade precária}

No item anterior apontamos algumas possibilidades de análise para a questão da transfobia ligada a assassinatos de pessoas trans; embora pareça redundante algumas militantes não enxergam uma ligação de fato, apontando situações particulares às execuções. No entanto, independentemente de haver um viés transfóbico na morte dessas pessoas, nota-se que uma série de exclusões vivenciadas proporcionaram um aumento da vulnerabilidade e da precariedade, o que tornam viáveis esses processos de execução.

A enorme incidência de episódios de transfobia que permeiam a vida dessas pessoas não assinala apenas uma violência gratuita, conforme discutimos, tem como objetivo reiterar normas e padrões tais quais o binarismo de gênero e a heteronormatividade, tornando certos sujeitos inteligíveis e passíveis de reconhecimento, e outros não. Em relação às pessoas trans negras, a transfobia pode se aliar ao racismo para eliminar corpos socialmente menos aceitos, mais questionados e hostilizados, não sendo coincidência que grande parcela de travestis e transexuais mortas no Brasil sejam negras (PEÇANHA, 2016).

Dessa maneira, é possível perceber como certos corpos não são notados no espaço público e na convivência social; isto no caso da população travesti e transexual vai muito além de uma

\footnotetext{
${ }^{4}$ Expressão apontada para designar o fato de ser vítima de algo, e não de se fazer/fingir de vítima, como se costuma fazer uso dessa expressão nos discursos da extrema direita no Brasil.
}

invisibilidade, pois ao sumirem não são declaradas desaparecidas, pelo menos pelo Estado ou pela mídia, oferecendo demonstração clara de que não existem para grande parte de seu estado.

Nesses casos as estratégias de desumanização se estendem a tantas dimensões quantas forem possíveis, pois se não há como ter gênero e nome reconhecido, educação básica, inserção no mercado de trabalho e vínculo familiar, as possibilidades de estarem inseridas em núcleos que "comprovem" sua humanidade e notem sua ausência vão sendo tombadas (como diriam as militantes) uma a uma. Desse modo

É importante reconhecer que um modo de "administrar" uma população é convertê-la em menos que humana, privando-a de seus direitos, tornando-a humanamente irreconhecível. Já não se trata de produzir um sujeito conforme a lei, ou um sujeito que tome as normas humanitárias como princípio constitutivo. Um sujeito que não é um sujeito não está nem vivo, nem morto, não está inteiramente constituído como sujeito, nem inteiramente destituído na morte. (BUTLER, 2006, p. 130).

Sendo assim, vale lembrar que no contexto alagoano essa realidade atinge a maioria, mas nem todas, pois algumas são mais dotadas de privilégios que outras. Cris de Madri e Natasha são exemplos de que apesar de poucas, ainda há diferenças nesse quesito, pois ambas possuem privilégios que lhes concedem alguma inteligibilidade humana, tais como trabalho formal e vínculo familiar, o que não é percebido com relação a outras militantes, a exemplo de Andreza:

Eles não vê a gente como ser humano, tá entendendo? Vê a gente como um bicho, como outra coisa, não vê a gente como humano, tá entendendo? Não dão muita oportunidade pra gente, não abre as portas pra gente, tá entendendo? E a gente precisa disso. (Andreza Fernandez, Entrevista em 17 de Dezembro de 2015).

Andreza aponta como compreende sua condição de ininteligibilidade e, consequentemente a impossibilidade de acessar o que se considera humano, embora tente se encaixar nas normas pelas quais se reconhece um humano, as mesmas dificilmente estarão a seu favor. Assim, entende-se que ainda que haja reconhecimento, a violência surge justamente para rompê-lo e 
questionar sua possibilidade, fazendo com que volte a ser irreal e impossível. De maneira que a transfobia que atinge Andreza e tantas outras não se constitui mera opressão, pois só seria possível oprimir aquele que é potencialmente inteligível e real.

Desse modo, a impossibilidade de serem inteligíveis em dados contextos as torna vulneráveis. No estado de Alagoas (como em muitos outros) o fato de terem renegado uma "macheza" naturalizada e exporem isso publicamente parece as tornar elegíveis para violências aplicadas como forma de castigo. Esse castigo, em sua forma micro, se transmuta na falta de credibilidade atribuída ao que essas sujeitas tem a dizer, em tornar cômica sua feminilidade, ou em sexualizar suas identidades a ponto de torná-las meros objetos sexuais, por exemplo. Tais atos se destinam a reforçar uma imagem de degeneração humana, que retira substancialmente o valor de qualquer vida a qual se vincule.

De maneira mais macro, a população de travestis e transexuais passa a constituir uma ameaça direta à vida de homens e mulheres que possuem como fundamento de suas vidas a coerência de gênero cisnormativa, a heterossexualidade, a rejeição à prostituição, a divisão entre primeira e segunda classe e a branquitude, por exemplo.

Isso faz com que não apareçam como vidas e sim como uma ameaça à vida (BUTLER, 2015), o que significa que serão eliminadas em prol da defesa dos ideais que constituem uma dada comunidade. Assim, ao executá-las estão afirmando: "não sentimos o mesmo horror e a mesma indignação diante da perda de suas vidas que sentimos com a perda das outras vidas que guardam uma semelhança [...] com a nossa própria" (IBID., p. 69).

Visto isso, vale a pena problematizar o enlutamento seletivo que tem tomado conta da sociedade e, fatalmente, o próprio movimento LGBT, pois se o fato de travestis e transexuais existirem apenas num contexto de exploração sexual (e isso não é sinônimo de prostituição) e de morte precoce, o que dirá aqueles que apresentam conformidade a norma.

No caso da população trans, essa desigualdade que atinge até a questão de enlutar-se, e especialmente o luto público, diz respeito não só à sociedade civil, como também ao Estado.
À medida que se retira vestígios de cidadania de certas pessoas por questões relativas à identidade de gênero, à medida que passam a ser classificadas dentro de uma categoria psicopatológica, ou à medida que se nega a criação de parâmetros inclusivos para a diversidade de gênero em dimensões básicas, dentre tantas variáveis, indica a quem o Estado destina o lugar de subalterno, de forma que não possa lhes restar o menor sinal de semelhança com o outro.

De acordo com Butler (2015) o luto público está diretamente vinculado à indignação, $\mathrm{e}$ essa indignação frente a injustiças cometidas e perdas irremediáveis adquire um caráter político, especialmente quando essas perdas nunca são tornadas públicas. Entendemos assim, que o movimento social trans de Alagoas tem um enorme desafio de fazer reconhecer vidas onde não se enxergam as mesmas, através do luto público.

\section{Considerações finais}

Compreende-se que o contexto da cidade de Maceió diz de uma resistência ao reconhecimento desses corpos como humanos, como vidas que carregam importância e devem ser preservadas, uma vez que o cenário de violência extrema contra sujeitas trans, em especial aquelas negras, é comumente naturalizado ou banalizado, indicando que há alguns degraus para que boa parte dessa população atinja o status de cidadãs, de fato.

A partir disso é possível compreender que ainda que haja certa visibilidade e protagonismo da população trans na cidade, trata-se de pessoas que exercem uma cidadania precária e que, portanto, não possuem meios para combater sozinhas o contingente de violência que as atinge. Isso indica que, em primeiro lugar, protagonizam uma luta sempre considerada menos legítima, $e$ em segundo lugar, que o Estado tem se furtado de promover o acesso aos direitos mais básicos para essa população e de aprovar leis, tais como a de identidade de gênero.

O próprio termo transfobia utilizado aparece como uma espécie de reconhecimento dessas identidades e da violência e preconceito que as atinge em função de serem travestis e transexuais. Assim, ao não aceitar homofobia como caracterização de crimes cometidos contra pessoas trans, evita-se o silenciamento de um perfil 
de hostilidade voltado exclusivamente para essa população.

Entender os mecanismos de propagação de preconceitos e atitudes violentas na capital alagoana tem se mostrado fundamental para enxergar as diversas formas de lutar contra uma realidade inaceitável, ainda que em alguns momentos as militantes aparentem resignação. O que constatamos é que esse cenário tem produzido um efeito contrário ao que se propõem os castigos às identidades trans, isto é, fazê-las sumirem, de modo que as travestis e transexuais da cidade tem desenvolvido sua resistência através do fortalecimento dos movimentos sociais e na promoção do cuidado de si mesmas.

\section{Referências}

BRASIL. Profissionais do sexo: Documento referencial para ações de prevenção das DST e da aids. Brasília: Ministério da saúde, 2002.

BRASIL. Relatório sobre violência homofóbica no Brasil: ano 2012. Brasília: Secretaria de Direitos Humanos da Presidência da República, 2013.

BUTLER, Judith. Deshacer el género. Barcelona: Paidós, 2006.

Problemas de gênero: feminismo e subversão da identidade. Rio de Janeiro: Civilização Brasileira, 2014.

Quadros de Guerra: quando a vida é passível de luto?. Rio de Janeiro: Civilização Brasileira, 2015.

Vida precaria: el poder del duelo y la violencia. Buenos Aires: Paidós, 2006.

BUTLER, Judith; ATHANASIOU, Athena. Dispossession: The Performative in the Political. Cambridge: Polity, 2013.

CAMPOS, Claudinei José Gomes. Método de análise de conteúdo: ferramenta para a análise de dados qualitativos no campo da saúde. Rev Bras Enferm, Brasília (DF), n. 57, v. 5, set/out 2004.

CAMPOS, Claudinei José Gomes; TURATO, Egberto Ribeiro. Análise de conteúdo em pesquisas que utilizam metodologia clínico-qualitativa: Aplicação e perspectivas. Rev Latino-am Enfermagem, v. 17, n. 2, março-abril, 2009.

CARRARA, Sérgio; VIANNA, Adriana R. B. "Tá lá o corpo estendido no chão...": a Violência Letal contra
Travestis no Município do Rio de Janeiro. PHYSIS:

Rev. Saúde Coletiva, Rio de Janeiro, n. 16, v.2, 2006.

CARVALHO, Mário Felipe de Lima. Que mulher é essa?: identidade, política e saúde no movimento de travestis e transexuais. Dissertação de Mestrado, Rio de Janeiro: Universidade do Estado do Rio de Janeiro, 2011.

CAZARRÉ, Marieta. Com 600 mortes em seis anos, Brasil é o que mais mata travestis e transexuais. Agência Brasil, EBC, 2015. Disponível em: < http://agenciabrasil.ebc.com.br/direitos-humanos/ noticia/2015-11/com-600-mortes-em-seis-anos-brasile-o-que-mais-mata-travestis-e>. Acesso em: 17 de Fevereiro de 2016.

$\mathrm{CIDH}$. Violencia contra Personas Lesbianas, Gays, Bisexuales, Trans e Intersex en América. Comisión Interamericana de Derechos Humanos, 2015.

DANTAS, Carolina. 'Representei a dor que sentimos', diz transexual 'crucificada' na Parada Gay. G1, 2015. Disponível em: < http://g1.globo.com/sao-paulo/ noticia/2015/06/representei-dor-que-sentimos-diztransexual-crucificada-na-parada-gay.html>. Acesso em: 20 de Novembro de 2015.

EURICO, Márcia Campos. A percepção do assistente social acerca do racismo institucional. Serv. Soc. Soc. São Paulo, n. 114, p. 290-310 abr./jun. 2013.

FIGARI, Carlos. @s “outr@s” cariocas: interpelações, experiências e identidades homoeróticas no Rio de Janeiro: séculos XVII ao XX. Belo Horizonte: Editora UFMG; Rio de Janeiro: IUPERJ, 2007.

FLICK, Uwe. Observação e etnografia. Introdução à pesquisa qualitativa. Porto Alegre: Artmed, 2009.

FONSECA, Claudia. Quando cada caso NÃO é um caso: pesquisa etnográfica e educação. Revista Brasileira de Educação, n. 10, Jan/Fev/Mar/Abr 1999.

GARCIA, Marcos Roberto Vieira. Prostituição e atividades ilícitas entre travestis de baixa renda. Cadernos de Psicologia Social do Trabalho, vol. 11, n. 2, pp. 241-256, 2008.

GGB. Assassinato de homossexuais (LGBT) no Brasil: Relatório 2014. Bahia: Grupo Gay da Bahia, 2015.

GGB. Quem a homotransfobia matou hoje?. GGB-36 anos: banco de dados, Bahia, 2016. Disponível em: < https://homofobiamata.wordpress.com/>.

GONÇALVES, Maurício. Travesti é torturado em Maceió. Gazeta de Alagoas [online], 20 de Agosto 
de 2013. Disponível em: < http://gazetaweb.globo.com/ gazetadealagoas/noticia.php?c=228677>. Acesso em: 2 de Fevereiro de 2016. Acesso em: 27 de Janeiro de 2016.

LARAÑA, Enrique. La construcción de los movimientos sociales. Madrid: Alianza Editorial, 1999.

MARQUES, Maikel. Estado registra crimes que chocaram. Gazeta de Alagoas [online], 28 de Junho de 2015. Disponível em: < http://gazetaweb.globo. com/gazetadealagoas/noticia.php?c=268685> . Acesso em: 27 de Janeiro de 2016.

MINAYO, Maria Cecília de Souza; SANCHES, Odécio. Quantitativo-Qualitativo: Oposição ou Complementaridade? Cad. Saúde Públ., Rio de Janeiro, v.9, n.3, p. 239-262, jul/set, 1993.

PEÇANHA, Leonardo. Visibilidade Trans: pra quem?. Negros Blogueiros, 2016. Disponível em: <http:// negrosblogueiros.com.br/leonardombpecanha/2016/ visibilidade-trans-pra-quem/>. Acesso em: 22 de Fevereiro de 2016.

PLATERO, Raquel (Lucas). ¿Es el análisis interseccional una metodologia feminista y queer? In: Otras formas de (re)conocer: Reflexiones, herramientas y aplicaciones desde la investigación feminista. Edição: Irantzu Mendia Azkue, Marta Luxán, Matxalen Legarreta, Gloria Guzmán, Iker Zirion, Jokin Azpiazu Carballo. País Basco: Lankopi, S.A, 2014.

PRINS, Baukje; MEIJER, Irene Costera. Como os corpos se tornam matéria: entrevista com Judith Butler. Estudos Feministas, Florianópolis, v. 1, ano 10, $1^{\circ}$ semestre de 2002.

SATO, Leny; SOUZA, Marilene Proença Rebello. Contribuindo para desvelar a complexidade do cotidiano através da pesquisa etnográfica em Psicologia. Psicol. USP, São Paulo, v. 12, n. 2, p. 29-47, 2001.

WAISELFISZ, Julio Jacobo. Mapa da violência: Mortes Matadas por Arma de Fogo. Brasília, 2015.

WAISELFISZ, Julio Jacobo. Mapa da Violência 2015: Homicídio de mulheres no Brasil. Brasília, 2015.

WAISELFISZ, Julio Jacobo. Mapa da Violência: Os Jovens do Brasil. Brasília, 2014.

WEBER, Florence. A entrevista, a pesquisa e o íntimo, ou por que censurar seu diário de campo?. Horiz. antropol., Porto Alegre, v.15, n.32, Dez., 2009. 